\title{
Toplum
}

\section{Göç ve İnsan}

\author{
Süleyman EKİCI ${ }^{1}$ \\ Gökhan TUNCEL ${ }^{2}$
}

\begin{abstract}
Öz: İnsanlar tarih içerisinde çeşitli nedenlerden dolayı yaşadığı mekândan ayrılmak durumunda kalmıştır. Göç kavramıyla ifade edilen bu ayrılık, insan ve mekân üzerinde çok yönlü bir etkiyi beraberinde getirmiştir. Göç başta birey olmak üzere insana dair olan inanç, düşünce, kural ve yapıların değişim ve dönüşüm yaşamasına zemin hazırlamıştır. Doğu- Batı arasındaki önemli bir geçiş güzergâhı olan Anadolu'da yıkılan ve kurulan medeniyetler için ayrı bir önemi bulunan göç, Türkiye için de üzerinde çok yönlü derinlikli çalışmalar yapılması gereken bir konu olmuştur. Bu çalışmada, insanların yaşadıkları doğal ve sosyal çevreyle kurduğu bağı zedeleme yanında ekonomik, sosyal, siyasal ve kültürel alanda birçok etkisi bulunan göç konusu farklı boyutlarıyla ele alınmaktadır.
\end{abstract}

Anahtar Kelimler: Toplum, göç, siyaset, kültür, sosyal yapı.

\section{Giriş}

Canlılar içinde özel bir yeri olan insan ve insana dair olanı değerli ve anlamlı kılan, bunların bulundukları mekânla kurduğu bağdır. Göç ise, insan ile mekân arasındaki bağı zedeleyen önemli unsurlardan biridir. Bireyler ve topluluklar çeşitli nedenlerden dolayı bulundukları 
mekânı terk ederek başka bir mekâna göç etmektedir. Birey ve topluluk açısından göç, mekânsal bir değişikliğe karşılık gelme (Özer, 2004: 11) yanında, birey ve toplumun anlam ve değer dünyasının da değişim ve dönüşüm yaşamasına de neden olmaktadır. Bu değişim ve dönüşümden terk edilen ve yerleşilen yeni mekânla birlikte, bu mekândaki insanlar ve insana dair olan her ne varsa onlar da nasibini akmaktadır.

Terk edilen ve yerleşilen yer ile göçenler ve göçülen yerdekilerin nitel ve nicel özelliklerindeki farklılıklar yanında göç nedeni, kapsamı ve işleyiş sürecinde farklılıklar her göçü bir diğerinden farklı kılmıştır (Yılmaz, 2014: 1692). Bu farklılıklar her bir göçün birey, toplum ve mekâna yönelik etkisinin ve yansımasının değişmesine neden olmuştur. Her ne kadar her bir göç hadisesi neden, işleyiş ve etki açısından kendine ait özellikler taşısa da göç konusunda bazı genellemeler yapılabilir. Bu çalışmada göç konusunda bu tür genellemeler yapılarak, göçün insan ve toplum üzerindeki etkisi farklı yönleriyle ele alınmaktadır.

Ekonomik nedenler ve güvenlik kaygısı başta olmak üzere pek çok neden insanların bulundukları mekânları kitleler halinde terk etmelerine neden olmuştur. Tarihsel süreç içerisinde insanlığın gündeminden çıkmayan veya insanların gündeminden çıkartamadığı bir konu olan göç, 2000'li yıllarda da dünyanın önde gelen gündemlerinden biri olmaya devam etmiştir. Özellikle 2010 yılında Kuzey Afrika'da ortaya çıkan ve daha sonraları Arap Baharı olarak ifade edilen süreç Türkiye’nin de içinde bulunduğu coğrafya başta olmak üzere dünyanın pek çok yerini doğrudan veya dolaylı olarak etkilemiştir.

Arap Baharının Suriye ayağı diğer ülkelerden farklı bir seyir izlemiş ve Suriye'de sınırları zorlayan bir şiddet sarmalı yaşanmış ve milyonlarca insan ülkeyi terk etmek zorunda kalmıştır. Çok kısa bir süre içerisinde milyonlarca insanın ülke dışına göç etmesi diğer komşu ülkeler yanında Türkiye’yi de büyük ölçüde etkilemiştir. Türkiye’ye göçen Suriyelilerin sayısındaki büyük artış, göçün etki alanını genişlettiği gibi göçün etkisinin derinleşmesine de neden olmuştur. Suriye'den Türkiye'ye yönelen göç akışı birçok yeni durumun ortaya çıkmasına neden olmuş, olmakta ve de olacaktır. 
Bu süreçte Türkiye'ye göç eden Suriyeliler, iletişim dünyasında habere konu, bazı sivil toplum kuruluşları ile düşünce enstitülerinde de rapora konu olmuştur. Özelde bu hadise genelde ise küresel ölçekte yaşanan kitlesel insan hareketliliği ve mülteci sorunu, göç konusunun farklı boyutlarıyla yeniden ele alınmasını gerekli kılmaktadır. Bu çalışma, göçün insana ve insana dair olana etkisi hakkında genel bir çerçeve çizme çabasının bir ürünüdür.

\section{Göç Kavramı ve Nedenleri - Türleri}

Canlı ile mekân arasındaki bağın aşınmasında önemli bir etkiye sahip olan göçün kavramsal bir çerçevesinin çizilmesi, neden ve türlerinin belirlenmesi göçün kısa, orta ve uzun vadedeki etkilerinin anlaşılabilmesi açısından oldukça önemlidir.

\subsection{Göç Kavramı}

Canlı ile doğduğu ve yaşadığı mekân arasında yakın bir ilişki bulunmaktadır. Canlılar içerisinde özel bir yeri olan insanın ve insana dair olanın oluşumunda ve gelişiminde sosyal çevre ile fiziki çevrenin önemli bir yeri bulunmaktadır. Sosyolojinin kurucularından kabul edilen İbn-i Haldun'un asabiyet teorisini çevresel koşullar üzerine bina etmesi de mekânın toplumsal yapı ve ilişkiler üzerindeki etkisini belirtmesi açısından oldukça manidardır. Mekânsal değişikliğe karşıllık gelen göç (Güvenç, 1996: 21), bireyin psikolojik durumu başta olmak üzere topluma dair olan hemen her şeyi etkileyen bir olgudur.

Göç, ekonomik yaşamda hem göçle gelenler ve hem de mukimler için yeni koşulların ortaya çıkarmaktadır. Bu koşullar bir taraftan ekonomiye dinamizm kazandırırken diğer taraftan yeni bir egemenlik ve sömürü ilişkisinin oluşumuna zemin harlamaktadır. Toplumsal yapılarda büyük çaplı değişime veya aşınmaya neden olan göç, yeni sorun ve fırsat alanlarını da içinde barındıran sınıfsal geçişkenliği hızlandırmaktadır. Sahip ol(a)mama durumu, sahip olma isteği ile yer bulma çabasının göçle gelenler açısından hayati öneme sahip olması, göçenlerin 
risk alma düzeyini yükseltmektedir. Risk alma düzeyindeki yükseliş ekonomik alana çoğu zaman olumlu yansırken siyasal ve sosyal alanda bir dizi olumsuzluğu beraberinde getirmektedir.

Tarih boyunca mekânlar, toplumsal ve siyasal aidiyet ve kimliklerin oluşumunda önemli bir etken olmuştur. İnanç, vatan, millet, devlet, etnisite, kavim, kabile ve aile gibi sosyal ve siyasal birlikteliklerin veya ayrışmaların oluşumunda mekân asli unsurlardan biri olmuştur. İçinde bulundukları mekânın koşullarına uyum sağlayıp sağlayamaması durumu ile bu tür yapıların hayatta kalma ve gelişim düzeyleri arasında doğrusal bir ilişki bulunmaktadır. Bu kapsamda toplumun en küçük yapı taşı olarak kabul edilen aile başta olmak üzere siyasal sistem veya medeniyetlerin gelişimi, aşınması, çözülüş ve çöküşünde mekânsal koşullara uyum konusunda yaşanan olumsuzlukların önemli bir yeri olduğu kabul edilmektedir. Ayrıca teknolojik gelişmeler insan ile mekân arasındaki ilişkiyi, birincisinin lehine bozmaya başlamıştır. İlişkideki bu bozulma insan lehine bir durum ortaya çıkartıyor algılansa da orta ve uzun vadede, insan ve insana dair olana yönelik birçok olumsuzluğu beraberinde getirmiştir (Çelik, 2012: 298-299). Büyük çaplı kitlesel göçlerin, insan ile mekân arasındaki ilişkinin bozulmasına hızlandırıcı ve derinleştirici bir etki yapmıştır.

Dünyanın pek çok yerinde göçe bağlı olarak büyük kentlerde hızlı bir nüfus artışı yaşanmıştır. Kentlerdeki hızlı nüfus artışı ekonomik alanda olduğu gibi sosyal ve siyasal alanlarda da yeni gerilim ve kutuplaşmaların ortaya çıkmasına neden olmuştur. Bu gerilim ve kutuplaşma, kentsel yerleşim ayrışması başta olmak üzere sosyal, kültürel ve ekonomik olanın siyasala evrilmesine zemin hazırlamıştır. Bu tür bir siyasallaşma, demokratik bir sistemde birey, sosyal grup ve sınıfların siyasal tercihleri üzerinde belirleyici bir ekti yaptığı gibi, şiddete eğilimli radikalize hareket ve yapıların da ortaya çıkmasını ve gelişmesini sağlamıştır.

Kentlileşme süreci geleneksel yapı ve ilişkileri aşındırdığı bir vakıadır. Kırda geleneksel yapı ve ilişkiler üzerinden hayatını sürdürenlerin kente göçmesi bu yapı ve ilişkilerin aşınma ve dönüşüm sürecine girmesini beraberinde getirmektedir. $\mathrm{Bu}$ süreç, kırdan koparak kente gelenlerin bir 
taraftan geleneksel yapı ve ilişkilerden uzaklaşmasına zemin hazırlarken diğer taraftan kentteki fiziki ve sosyal yapılara karşı yabancılaşma duygusu içine girmesini sağlamaktadır. Kentli nüfusun, bu kesime yönelik dışlayıcı bir tutum içerisine girmesi bu yabancılaşma duygusunu derinleştirmekte ve bu kesimin kente yönelik bir aidiyet hissi geliştirmesinin önünde engel oluşturmaktadır. Kente yönelik aidiyet hissinin gelişmemesi, akrabalık, kabilecilik gibi geleneksel veya hemşehricilik gibi yeni ilişki ağlarının kentsel yapılarda sürdürülmesi gibi ikircikli bir durumun ortaya çıkarmaktadır. Kentsel değer, kurum ve kurallar göçle gelenler için çoğu zaman bir anlam ifade etmemektedir. Nirengi noktası kentte var olma, kalabilme ve güçlü olma olan bu insanların kentsel olanla barışık bir yaşam sürmesi oldukça zordur.

Kentlileşme sürecinin beslediği bireyselleşme, insanın özgürleşmesine önemli bir katkı sunmaktadır. Ancak ketlerdeki bireyselleşme süreci bir taraftan insanı özgürleştirirken diğer taraftan insanı geçmişe ve hayata dair birçok şeyden uzaklaştırmakta, bir nevi köksüzleştirmektedir. Bu durum da sosyal bir varlık olan insanın karşılaştığ 1 pek çok soruna zemin hazırlamaktadır.

\subsection{Göç Nedenleri}

İnsanlar yaşadıkları mekânları çeşitli nedenlerle terk etmek durumunda kalmışlardır. İnanın iradesi dışında gelişen doğa hadiseleri tarihsel süreç içerisinde göçün en önemli nedenlerini oluşturmuşken, sanayi devrimi sonrasında asli belirleyicisi insan olan ekonomik, siyasi ve sosyal nedenler göçün en önemli nedeni haline gelmiştir (Keleş, 1983: 6). Özellikle ulaşım ve iletişim araçlarındaki gelişmelere paralel olarak insanların daha iyi bir hayat sürme istekli göçlerde (Sencer, 1979: 28) büyük bir artış olmuştur. Özellikle güney yarım küreden kuzeye ve doğudan batıya doğru büyük çaplı göç hareketleri ortaya çıkmıştır.

Göçe neden olan unsurlar, göç süreci ve sonrasındaki gelişmeleri de büyük ölçüde etkilemiştir. Ekonomik nedenleri göçler, siyasi nedenli göçlerden farklı bir sürecin işlemesine neden olabileceği gibi farklı ekonomik, sosyal ve siyasi sonuçların ortaya çıkmasına da neden olabilir. 
Siyasi nedenli göçler, bilinçli ve keskin bir siyasallaşma duygusuna, radikal siyasi eğilimlere, güçlü bir diasporanın oluşumuna ve toplumsal entegrasyon konusunda dirençli bir grup psikolojisine sahip olmaya zemin hazırlamaktadır.

\subsection{Göç Türleri}

Göç, insanların veya toplulukların kendi iradeleriyle gerçekleşen özgür bir seçim olabileceği gibi kendi iradeleri dışındaki gelişmelerin bir sonucu gerçekleşen zorlama bir süreç şeklinde de ortaya çıkabilir. Göç, bireysel bir süreç olabileceği gibi kitlesel bir dalga şeklinde de yaşanabilir. Göçün nasıl gerçekleştiğinin bilinmesi, göçün etki boyutunun anlaşılmasına yararlı olacaktır.

Sürece yayılan ve sürdürülebilirliği olan bir tür olarak iradi (gönüllü) göçün ekonomik, siyasal ve sosyal olan yansıması doğal afetler veya savaş, terör, sürgün gibi güvenlik kaygılarından (Çobanoğlu, 1996: 12) dolayı ortaya çıkan zorunlu göçün yansımasından farklı olmaktadır. Daha iyi bir yaşama kavuşma arzusundan dolayı, insanın bulunduğu mekânı terk etmesine karşılık gelen iradi göçte ekonomik olanın belirleyiciliği söz konusu iken, insanın öncelikli olarak sığınacak bir yer arayışı içerisinde olduğu zorunlu göçlerde ise çoğu zaman siyaset daha bir belirleyici unsur olmaktadır.

Göçün iradi veya zorunlu olmasının yanın da sayısal büyüklüğü de göçün etki boyutunda önemli belirleyici bir unsurdur. Uzun bir süreçte bireysel veya küçük çaplı göçlerle, kısa sürede büyük kitlesel göçlerin etki boyutu oldukça farklı sonuçlar meydana getirmektedir. Özellikle siyasal iktidarların karşılamada zorlandığı veya karşılayamadığı kitlesel göç dalgaları mekânsal, sosyal ve siyasal birçok karmaşık sorunun ortaya çıkmasına zemin hazırlamaktadır (Li, Frieze, 2012: 5-8).

\section{Göçmenler ve Terkedilen Yer Açısından Göç}

Sosyal bir varlık olan insanın, bedeni ve sosyal gereksinimleri, içinde bulunduğu doğal ve yapay çevre aracılığıyla karşılanmaktadır. İnsan 
olmak ve insan kalmakla da doğrudan ilişkili olan çevresel koşullar, insana dair olan hemen her şeyin, ortaya çıkmasını sağladığı gibi, hayat bulmasını sağlayan imkânları içerisinde barındırmaktadır. İnsanın yaşadığı mekândan ayrılarak başka bir mekâna yerleşmesine karşılık gelen göç, insan üzerinde önemli etkilerde bulunma yanında insanların ayrılmak durumunda kaldıkları mekânları da birçok yönden etkilemektedir.

Göçle yeni bir mekâna yerleşen insan, bir taraftan yeni mekâna alışmaya ve bu mekânda kendisine alan açmaya ve yer tutmaya çalışırken diğer taraftan hayatta kalma, yok olmama, sahip olduklarını (maddimanevi) kaybetmeme çabası içerisine girmektedir. İnsanı dinamik bir hayat yaşamasını zorunlu kılan bu tür süreçler, insanın ayakta kalabilme, var olma veya kazanabilmek için çok yönlü bir iktidar savaşımına dâhil olmasını da beraberinde getirmektedir. Göçmenler, göçtükleri yerdeki toprak, şehir ve siyaset başta olmak üzere hemen her şeyi iktidar aracı veya engeli olarak görmektedir (Cengiz, 2010: 188). Göçmenlerin bu tür bir yaklaşıma sahip olması yerleştikleri yeni mekândaki doğal ve yapay çevrede büyük çaplı değişimlerin oluşumuna altyapı hazırlamaktadır.

Göçmenlerin göçtükleri yeni mekânda hayatta kalabilmesi ve güçlü olabilmesi, benzer özelliklere sahip toplumsal kesim veya kesimlerle güçlü bir dayanışma ilişkisi içerisinde birlikte hareket etmesine bağlı olmuştur. Ayrıca, kaybedecekleri çok az şeyi, buna karşın kazanabilecekleri birçok şey bulunan göçmenlerin, risk alma düzeyi yerleşik insanlara göre genellikle daha yüksek olmuştur. Dayanışma ve risk alma düzeyindeki yükseklik, göçmenlerin güçlü bir yenileme potansiyeline (devrimsel değişimlere) sahip dinamik bir yapıda olmasına ve kendilerine yeni fırsat alanları açmasına önemli katkılar sağlamaktadır.

Göçmenler, yeni mekânlarında hayatlarını sürdürmeleri için sahip oldukları bu olumlu özellikler yanında kendileri ve çevreleri için orta ve uzun vadede yeni birçok karmaşı sorunun ortaya çıkmasına zemin hazırlayacak bazı özellik ve durumlara da sahip olmuşlardır. Çevresel koşullara adapte olmama durumu ile kamusal hizmetlerin asgari düzeyde dahi karşılanamaması durumu göçle gelenlerin gecekondu tipi yapılaşma (Tatlıdil, 2002: 358), dolmuş tipi toplu ulaşıma araçları gibi kendine özgü geçici ve çözümlere yönelmesini beraberinde getirmiştir. 
Kentlileşme gibi bir değişim ve geçiş sürecine dâhil olan göçmenler, kendilerine ait olanı sürdürmede, yinelemede ve aktarımda zorlanmışlardır. Bu zorlanma arabesk tarzı ara bir kültürün ortaya çıkmasına zemin hazırlamıştır. Kentlileşme sürecinde göçmenler bir taraftan dönüşmüş, diğer tarafta ise dönüşürken dönüştürmüşlerdir. Dönüştürme süreci, daha çok iktidara gelme ve iktidarda yer bulma şeklinde gerçekleşmiştir. Göçmenler için çok fazla anlam ve değer taşımayan birçok doğal güzellik, kültürel değer ve tarihi eser bu dönüşüm sürecinden olumsuz etkilenmiştir. Ayrıca, kitlesel göçler fiziki, ekonomik ve sosyal birçok yeni sorunun ortaya çıkmasına neden olduğu gibi, insan hakkı bağlamında yeni bir sorun ve durumun ortaya çıkmasına da zemin hazırlamıştır.

Kırın iticiliği ve kentin çekiciliği (Ficher, 1994: 155-156) genel yargısı üzerinden anlamlandırılmaya çalışılan göç süreci terk edilen kırsal mekânlarda yaşayan insan sayısında azalmaya neden olmuştur. Kırsaldaki nüfus azalması bir yandan bu yerlerin fiziki açıdan viraneye dönmesine neden olurken, diğer yandan bu yerlerdeki sosyal yapı ve ilişkilerin büyük bir değişim yaşamasına da zemin hazırlamıştır. Yaşanan bu değişimin nedeni sadece nüfustaki azalma olmamış, kente göçenlerin kentlileşme sürecinde yaşadıkları değişimi kıra aktarmaları da bu değişimin ortaya çıkmasına büyük bir katkı sunmuştur. Ayrıca, ulaşım ve iletişim araçlarındaki gelişme ve yaygınlaşma da kırdaki değişimin farklı bir evreye girmesine neden olmuştur.

\section{Gelinen Yer Açısından Göç}

Hızlı göç hareketleri, kentlerdeki yerleşim alanlarında genişlemeye neden olmuştur. Yeni yerleşim yerine duyulan ihtiyaç, bu ihtiyaca kamu otoritesinin karşıllık verememesi ve bunun sonucunda plansız yeni yerleşim yeri açılması yeni birçok durum ve sorunun ortaya çıkmasına zemin hazırlamıştır (Kıray, 1998: 92). Çarpık kentleşme ile kaçak yapılaşma gibi altyapı sorunlarının yanında yaşanan kentlileşememe durumu, süreci daha bir sorunlu hale getirmiştir. Yerleşik insanın kentle ilişkisinin göçle gelenlerden farklı olması, kentlerin fiziki yapısı yanında kimyasının da bozulmasına neden olmuştur. 
Hızlı nüfus artışı, kentlerde ekonomik, sosyal ve siyasal alanda yeni bir paylaşım sorunu ortaya çıkarmıştır. Bu paylaşım sorunun zemin hazırladığı rekabet ortamı, sahip olduğunu kaybetme algısı ve korkusu üzerinden yükselen mikro ve etnik düzeyli bir milliyetçilik duygusunun oluşumunu beraberinde getirmiştir. Bu tür milliyetçi duygular kentlerdeki toplumsal kutuplaşma ve gerilimleri besleyerek, gerilim ve kutuplaşma düzeyi yüksek dışlayıcı bir siyasallaşma sürecinin yaşanmasına altyapı hazırlamıştır. Bu tür bir siyasallaşma sürecinin yaşanması da kentlerde ve ülkede demokratik kültür, yapı ve işleyişin oluşum ve gelişimine engel olmuştur.

Kentlerde var olan düzen ve sistemin dönüşüm yaşamasına neden olan göç, birçok alanda istikrarsızlığı ortaya çıkarmıştır. Toplumsal alanda birçok kırılmanın yaşanmasına neden olan istikrarsızlık, kültürün oluşumunda ve gelişiminde önemli bir etkisi bulunan geleneğin yenilenememesi (yeniden üretilememesi) sorununu beraberinde getirmiştir. Bu sorunun aşılamaması da toplum ve kent için hayati öneme sahip değer, kural ve kurumların işleyişini olumsuz yönde etkilemiştir. Değer yargısından uzak kalmaya, kural ve kurumlara olan bağlil1ğın düşüşüne neden olan göç, kentlerdeki suç türlerinin ve oranlarının artışında büyük bir etkiye sahip olmuştur.

Göçler, ülke ekonomisi yanında kentteki ekonomik yaşamı, etkisi boyutuna bağlı bir şekilde etkilemiştir (Massey, vd., 2014: 42). Göç, işsizlik artışına, kamusal harcamaların artmasına, harcama kalemlerinin sıralamasının değişmesine, vergi artışına, kayıt dışılığın artmasına, çalışanların ücretlerinde düşüşe, gayrimenkul fiyatları ile kiralarda artışa ve haksız rekabet koşullarının ortaya çıkmasına neden olmaktadır. Ancak, göçün ekonomiye yeni ve dinamik bir iş gücü kaynağı sağladığı (Ersoy, 1985: 8-9) ve belki bundan da önemlisi kazanma hevesi yüksek bir toplumsal kesimin ekonomik alana taşınmasına aracılık ettiği, dolayısıyla da ekonomiye önemli bir katkı yaptığı gerçeği göz ardı edilmemelidir.

Demografik yapının değişmesini sağlayan göç, yeni bir çevrenin ve ilişkiler ağının ortaya çıkmasına zemin hazırlamıştır. Bireyselleşme düzeyinin arttığı kentlerde göçle birlikte yeni bir tür cemaatimsi yapılanma 
ve ilişki biçimi ortaya çımıştır. Kent ve kır arasında sıkışan bireylerde ve toplumsal yapılarda çeşitli gerilim alanları ortaya çıkmıştır. Göçle gelenlerin kentsel ortamda kıra özgü bir hayat sürme istekleri, çoğu zaman, entegrasyonu geciktirmiştir. Ekonomik ve sosyal maliyeti artıran bu gecikme, yeni birçok sorunun da ortaya çıkmasına zemin hazırlamıştır.

Kentte kendisini yabancı gören göçmenlerin toplumsal dışlanmaya maruz kalması veya dışlanma duygusuna sahip olmasının sosyal hayata olumsuz yansımaları olmuştur. Göçmenlerin asimilasyon politikaları aracılığıyla eritilerek kendisi olmaktan çıkartılması ve kendisi için değerli olana değer verilmemesi durumu da sosyal hayatı olumsuz yönde etkileyen diğer bir durum olmuştur.

2010'lı yılların başında Suriye'de ortaya çıkan iç savaş durumunun neden olduğu, bölgedeki birçok diğer ülke gibi belki de onlardan daha çok Türkiye'yi etkileyen, kitlesel göç bazı gerçeklerin yeniden ülke gündemine taşımıştır. Suriye göçü gelinen yere göçün somut etkilerinin açılanması açısından önemli veriler ve bilgiler sunmuştur. Suriye'deki iç savaştan kaçıp Türkiye’ye göçenlerin bir bölümü denetimli yığınlar olarak planlı ama geçici konaklama merkezlerinde barındırılırken, göçenlerin büyük bir bölümü ise denetimsiz yığınlar olarak ülke içerisine dağılmışlardır. Merkezi idarenin, dolaylı olarak aslında halkın, yükünü artıran bu kitlesel göçün maliyet hesabında çoğu zaman denetimli yığınlar için yapılan harcamalar dikkate alınırken, yerel yönetimler ile mukimlerin yükünü artıran denetimsiz yığınlar bu hesaba dahil edilmemiştir. Suriye'den Türkiye'ye kitleler halinde göçenlerle ilgili olarak, yükü çeken ile kararı veren arasındaki ilişki düzeyinin katılımcı demokrasi bağlamında yeni bir sorgulamaya tabi tutulması söz konusu olmuştur.

Suriye hadisesi, göçün sosyal doku, yapı ve ilişkiler üzerindeki etkisinin yeni baştan gözden geçirilmesini gerekli kılmıştır. Göçenler arasında kadın ve çocukların oranındaki yükseklik, sosyal yaşamda yeni durum ve sorunların ortaya çıkmasına neden olmuştur. Suriyelilerin yoğun olarak göçtüğü ve yerleştiği kentlerde, sosyal yaşamın önemli unsurlarından komşuluk ve evliliklerde yeni gerilim alanları ortaya çıkmıştır. Bu kentlerde Suriyeli kadınlarla evliliklerin artmasına bağlı olarak boşanma sayısında artış olduğu gözlenmiştir. 


\section{Göçün Etki Boyutu}

Bireyin doğduğu ve içinde bulunduğu mekânla olan bağının zedelenmesine neden olan göç, insanın moral dünyasında birçok sorunun ortaya çıkmasına neden olmaktadır. Sağlıklı insan bir yönüyle, doğal veya sosyal çevresiyle uyumlu insana karşılık gelmektedir. İnsanların sahip olduğu inanç, düşünce, hayal, alışkanlıkları, tutum ve davranışlarında çevresel ortamın önemli bir etkisi bulunmaktadır. Bir yönüyle çevresel ortam değişimi anlamına gelen göç, bireyi yeni bir gerilim, stres ve psikolojik travma alanına yönelimini sağlamaktadır.

İnsanlar, toplumlar ve ülkeler arasındaki ilişki ve etkileşimin ortaya çıkışında ve gelişiminde göçün ayrı ve önemli bir yeri bulunmaktadır. İnsanın bulunduğu sosyal ve doğal çevreden ayrılarak başka bir mekâna yerleşmesi, ekonomik, sosyal, siyasi ve kültürel geçişkenliğe zemin hazırlamakta ve bu geçişkenliği hızlandırmaktadır. Tarihsel süreç içerisinde savaş, ticaret ve göç geçişkenliğin asli araçları iken 1900'lu yılların ikinci yarısından itibaren iletişim araçlarındaki gelişme ve yaygınlaşma bu geçişkenliğin asli unsuru olmaya başlamıştır. İletişim araçları, daha çok gelişmiş Batı toplumlarının belirleyiciliğinde yürüyen bir sürecin aracı olarak kullanılmıştır. İki yönlü bir ilişkinin (etkileşimin) ortaya çıkmasına zemin hazırlayan göç ise, maddi ve manevi açıdan medeniyetin gelişimine çok yönlü bir katkı sağlamıştır.

Toplumsal ve kültürel geçişkenlik üzerinden insanlığın gelişimine önemli bir katkı sunan göç, toplumların ve ülkelerin yaşadığı birçok sorunun yayılma ve yaygınlaşma sürecini de hızlandırmış ve derinleşmiştir. Göç, sosyal ve kültürel alandaki farklılıklar ile ekonomik alandaki menfaat çakışmalarının siyasal alana taşınarak, siyasal alanda karmaşık bir mücadele zemini oluşturmuştur. Ayrıca göç, siyasal alandaki rekabette, kutuplaşma ve radikalleşmenin ortaya çıkmasına kaynaklık etmiştir.

Tolumda uzun bir sürece yayılmış olan evrimsel değişimden hızlı devrimsel değişimlere geçişte göçün önemli bir etkisi bulunmaktadır. $\mathrm{Bu}$ yönüyle yenileyici bir özellik taşıyan göç, bir yönüyle insanlık birikimi olan geleneğin ve geleneksel olanın ortadan kalkmasını ve işlevsizleşmesini de sağlamıştır. 


\section{Sonuç}

İnsan ve insana dair olan hemen her şeyi etkileme potansiyeline sahip bir olgu olan göç tarihin hemen her döneminde farklı yönleriyle ele alınması gereken bir süreci ortaya çıkarmaktadır. Göçe neden olan etmenler ile göç sürecinin izlediği seyir, göçün etkileri üzerinde belirleyici olmaktadır. Göç, farklı yönleriyle irdelenmesi gereken bir konu olmanın yanında, yansımalarının öngörülmemesi halinde daha sonra üstesinden gelmenin pek mümkün olmadığı pek çok soruna zemin hazırlama potansiyeli taşıyan bir olgudur. Oysa, farklı bileşenleri olan ve çok boyutlu bir etkiye sahip olan göç olgusuna, birçok ülkede sadece sosyal politikayla ilgili bir olguymuş gibi yaklaşılmaktadır (Borjas, 1994: 1714).

İyi yönetilen göç süreçleri ile kapsamlı ve ayrıntılı hazırlanan göç politikaları toplumların ve ülkelerin yaşadıkları durağanlığın aşılmasında, dinamik bir ekonomik alanın oluşumunda önemli işlevler görebilir. Göçün kamu otoritesi tarafından karşılanamaz bir hal alması durumunda ise insana dair olan hemen her şeyi olumsuz yönde etkileyen bir süreç ortaya çıkacağı tarihsel ve toplumsal bir gerçekliktir.

Sosyal bilimlerin önemli çalışma alanlarından birisi olan göç konusu olmasının yanında Türkiye toplumunun hayatında önemli bir yer tutan göç, uzun yıllar ihmal edilmiştir. Oysa Anadolu tarihi bir yönüyle göçler tarihidir. Türkiye'deki hemen her birey ve toplumsal kesim ile hemen her mekânın üzerine sinmiş bir etkiye sahip göç, kapsamlı, ayrıntılı ve derinlikli çalışmalar yapılması bir konudur. Birçok konuda olduğu gibi göç konusu da olan olduktan ve iş işten geçtikten sonra üzerinde durulan bir konu olmamalıdır. 


\section{Kaynakça}

Borjas, George J. (1994), “The Economics of Immigration”, American Economic Assocation, Vol. 32, N.4, pp. 1667- 1717

Cengiz, Semran (2010), "Göç, Kimlik ve Edebiyat", Zeitschrift für die Welt der Türken, Vol. 2, No.3, pp.185-193

Çelik, Celaleddin (2012), “Göç, Kentleşme ve Din”, Din Sosyolojisi, (Ed.

N. Akyüz, İ. Çapcıoğlu), Ankara: Grafiker Yayınları, ss.297-306

Çobanoğlu, Zekai (1996), Konut Sağlı̆̆ı, Ankara: Somgür Yayınevi

Ersoy, Melih, (1985), Göç ve Kentsel Bütünleşme, Ankara

Fıchter, Joseph (1994), Sosyoloji Nedir? (Çev. N. Çelebi), Ankara: Atilla Kitabevi.

Güvenç, Bozkurt (1996), “Göç Olgusu ve Türk Toplumu”, II. Ulusal Sosyoloji Kongresi: Toplum ve Göç, Mersin: Sosyoloji Derneği Yayınları

Keleş, Ruşen (1996), Kentleşme Politikaları, Ankara: İmge Yayınevi

Kıray, Mübeccel (1998), Kentleşme Yazıları, Ankara: Bağlam Yayınları

Li, Manyu, Irene H. FRIEZE (2012), "Before The Big Decision: Psycological Theories on Premigration Motivation", Immigration Polisicies, Challenges and Impact (Ed. E. Tartakovsky), New York: Nova Publishers, pp.3-27

Massey, Douglas S. vd. (2014), "Uluslararası Göç Kuramlarının Bir Değerlendirmesi”, (Çev. S.

Dedeoğlu, vd.), Göç Dergisi, C.1, S.1, ss.11-46

Özer, İnan (2004), Kentleşme, Kentlileşme ve Kentsel Değişme, Bursa: Ekin Kitabevi

Sencer, Yaşar (1979), Türkiye'de Kentleşme, Ankara: Kültür Bakanlığ1 Yayınları

Tatlıdil, Ercan (2002), “Kentleşme ve Göç”, Sosyolojiye Giriş, (Ed. İ. Sezal), Ankara: Martı Yayınevi 
Yılmaz, Abdurrahman (2014), "Uluslararası Göç: Çeşitleri, Nedenleri ve Etkileri”, Turkish Studies, Vol.9, N.2, pp.1685-1704

Abstract: -Migration and Human - In history people were forced to leave the place where lived for several reasons. It expressed the separation with the concept that migration has brought about a multi-faceted impact on human and place. Migrate changes and converts especially individuals belief, thoughts, rules and social structures. In this study, it is examined that causes and types and results of migration that damage relations of people that created natural and social environment. It also describes the migration of economic, social and political effects. In this study the migration, which is important for civilizations established and destroyed in Anatolia where an important transit route between the East and the West, is discussed with different aspects.

Key words: Society, immigration, politics, culture, social structure. 